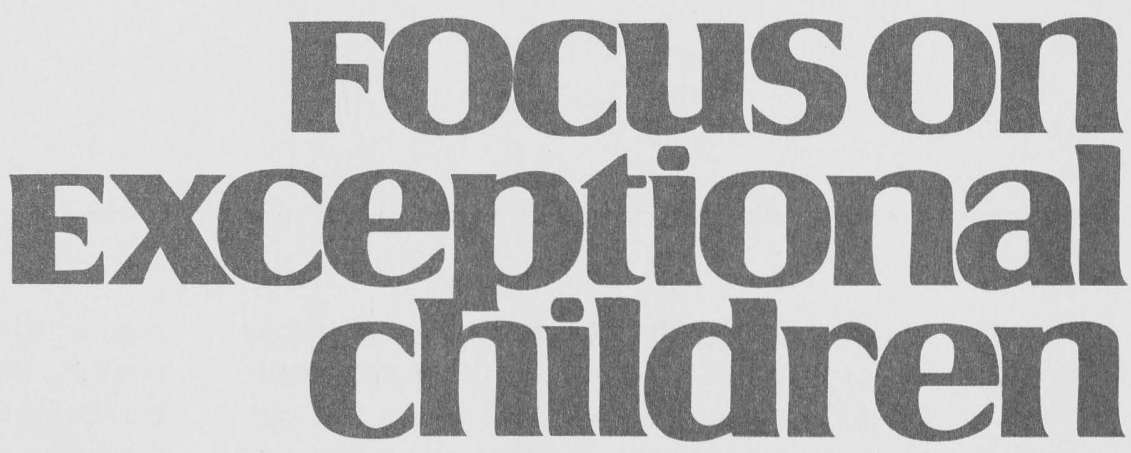

\title{
Curriculum Considerations in an Inclusive Environment
}

\author{
Cynthia D. Warger and Marleen C. Pugach
}

Ms. Grant has taught special education for more than a decade. This year her school moved to an inclusive model. Students who previously had been assigned to Ms. Grant's resource room are going to be included fully in a fifth-grade classroom taught by Ms. Howard. Ms. Grant has collaborated in the past with Ms. Howard, primarily in applying behavior management techniques to solving students' problems. Given this new arrangement, however, she knows that more is needed to support the students' progress.

At Stone Middle School, eighth-grade teachers want to implement an interdisciplinary curriculum unit for students across classrooms. Teachers feel strongly that special education students should be included in the project work. They have called upon Mr. Pack, the special education teacher, to assist with the planning and instruction. In the past Mr. Pack worked with special education students on basic literacy skills but now realizes that to pull his weight on the interdisciplinary team, he will have to do more.

Special education teacher Ms. Barker and history teacher Mr. Marley have been coteaching for the last year. Occasionally Ms. Barker provides actual instruction to the class, but her role consists primarily of tutoring individual students. The district just announced that the social studies curriculum will undergo renewal next year. Although Ms. Barker is pleased with the progress students have been making as a result of her interventions, she is beginning to think that much more could be done if certain changes were made to curriculum before presenting it. She wishes there would be a way to contribute to curriculum planning.

As these vignettes suggest, the movement toward increased inclusive placements for students with disabilities is changing the role of the special education teacher. As special educators are expected to deliver more and more of their educational support within the general classroom context, new opportunities to reconfigure traditional specialized services abound. Collaboration between general and special educators has long been an important means of fostering this change. Unlike the collaboration typically found in noninclusive programs, in which the major focus is on the special educator solving individual student problems, however, collaborative partnerships now face the challenge of expanding to include curriculum planning and implementation. As educators share responsibility for all students, what students know and are expected to do-which are fundamental questions of curriculum-have become the concern of all educators.

Dr. Warger is associated with Warger, Eavy, \& Associates. Dr. Pugach is on the faculty of the University of Wisconsin-Milwaukee. 
In this article, we explore how teacher collaboration can be expanded specifically to include curriculum considerations and to offer a process by which teachers can work together to address these concerns. Whether the special educator is serving as a co-teacher, a teacher consultant, or a member of a prereferral team, issues related to curriculum should be moving to the forefront of discussions in inclusive contexts.

\section{CURRICULUM AS THE NEW TARGET OF COLLABORATION}

In the context of inclusive schools, students with a wide range of learning and behavioral characteristics are not themselves considered so much a part of the problem. Instead, the challenge is to create learning environments that promote suc-

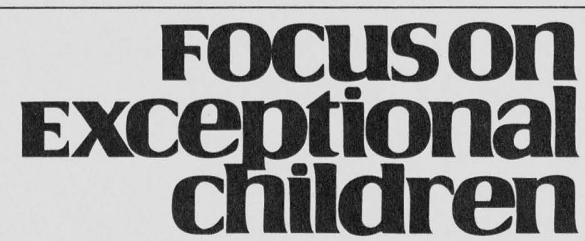

ISSN 0015-511X

FOCUS ON EXCEPTIONAL CHILDREN (USPS 203-360) is published monthly except June, July, and August as a service to teachers, special educators, curriculum specialists, administrators, and those concerned with the special education of exceptional children. This publication is annotated and indexed by the ERIC Clearinghouse on Handicapped and Gifted Children for publication in the monthly Current Index to Journals in Education (CIJE) and the quarterly index, Exceptional Children Education Resources (ECER). The full text of Focus on Exceptional Children is also available in the electronic versions of the Education Index. It is also available in microfilm from Xerox University Microfilms, Ann Arbor, MI. Subscription rates: Individual, $\$ 30$ per year; institutions, \$40 per year. Copyright @ 1 1996, Love Publishing Company. All rights reserved. Reproduction in whole or part without written permission is prohibited. Printed in the United States of America. Second class postage is paid at Denver, Colorado. POSTMASTER: Send address changes to:

$$
\begin{gathered}
\text { Love Publishing Company } \\
\text { Executive and Editorial Office } \\
\text { P.O. Box } 22353 \\
\text { Denver, Colorado } 80222 \\
\text { Telephone (303) } 757-2579
\end{gathered}
$$

Edward L. Meyen

University of Kansas

Richard J. Whelan

University of Kansas Medical Center
Kristin Kennedy Editorial Assistant cess for all students. As a result of the focus shifting from problems within students to how classroom work is designed, the relationship between students, particularly those with mild disabilities, and the curriculum, requires a reconceptualization as well (Pugach \& Warger, 1993; Warger \& Pugach, 1996).

Curriculum, after all, is at the heart of schooling. As many special educators often have observed, students who increasingly are being included in general education classes are the same students who were excluded in the first place because of their unsuccessful performance in the standard curriculum. So if special education teachers are to make serious contributions to the success our students achieve in inclusive settings, they must be prepared to address the curriculum itself.

The standard curriculum continues to pose problems for students with disabilities, and thus affects the ease and success with which integration can take place (McLaughlin \& Warren, 1992; NASBE, 1992). Too often, students are denied access to the curriculum simply because they do not have the prerequisite skills that will allow them to participate in the lesson. In other cases the problem lies with the structure and content of the curriculum itself. Difficulties arise when the content is at a cognitive level that is too high, requires analytic skills that the student does not have, or assumes a certain knowledge base that is not present. If the curriculum is deemed the problem, the challenge that ought to take priority is to rethink what the student is being asked to do and whether it is appropriate given students' unique learning and behavioral characteristics.

For many special and general educators this description of curricular problems may seem obvious. What creates the current challenge for educators working in inclusive settings is to frame classroom dilemmas from a proactive perspective in which the target of the intervention is the curriculum and its relationship to the student rather than the student alone. The goal becomes one of planning learning environments that, from the onset, result in the highest learning achievement for the most students possible. At the same time, emphasis is placed on identifying how the curriculum might be making unreasonable demands on learners, rather than assuming that "this growing number of students" is what is presenting unreasonable instructional challenges to teachers.

This seemingly subtle distinction has some significant implications for how special and general education approach "business as usual." In traditional, noninclusive programs, when a student is not achieving the curriculum goals, the ten- 
dency is to look at the deficit behavior or learning characteristic as the sole source of the problem. To improve inclusive programs so they support student success, we can shift the source of the problem to the curriculum itself and how it is delivered in the classroom. The goal is to reassess what the student is being asked to learn and how the knowledge and skills are being presented. In doing this, special and general education teachers ask themselves what they can do together to improve the student's relationship with the curriculum. The role of special education support personnel takes on new meaning when interventions are framed from the perspective of (a) how reasonable the curriculum is in the first place, and (b) how to adapt and modify the curriculum based on a sound understanding of curriculum goals.

Over the last few years we have worked with special and general educators alike to refocus their thinking about inclusion onto curriculum (Pugach \& Warger, 1993; Pugach \& Warger, in press; Warger \& Pugach, 1993) and to use it as an entry point when collaborating about how to redesign classrooms to accommodate a wider range of learners. We have found that, by targeting curriculum rather than student deficits as the jumping-off point for discussions between general and special educators, we have a much better chance of eliminating barriers to student success-whose origins more often than not can be traced to rigid conceptions of curriculum in the first place.

\section{COLLABORATIVE PARTNERSHIPS: A LOGICAL STARTING POINT}

Children's unique learning needs finally are being recognized as the norm rather than the exception in our nation's schools. For several years, one way that school districts have been addressing the ever widening diversity of student needs in general education classrooms is through collaborative partnerships between general and special educators. Coteaching, collaborative consultation, peer collaboration, prereferral teams, teacher assistance teams - to name a feware among the most widely practiced methods for promoting successful inclusion of students with mild learning and behavioral disabilities (Laycock, Gable, \& Korinek, 1991; McLaughlin \& Warren, 1992; National Association of State Boards of Education, 1992).

The intent of these collaborative partnerships undoubtedly has been to put energy and resources into preventing school failure by implementing modifications or accommodations of standard, normative practice in general education classrooms specifically to meet the needs of students who are experiencing academic or behavioral difficulties. Most collaborative interactions, however, still revolve around the old special education paradigm in which the focus of problem solving is on the individual characteristics or performance deficits that pose instructional dilemmas for teachers.

As we move toward more inclusive classrooms and schools, professional collaboration between special and general education teachers is more important than ever. Because the basic structure and content of general education classrooms will without question determine the success of inclusion, however, we can no longer simply move students with disabilities out of resource rooms and into the mainstream, tinkering with accommodations to and modifications of the existing curriculum along the way. Instead, inclusive education demands that we rethink our basic conceptions of teaching and learning, which essentially means rethinking the curriculum itself - not only for students with disabilities, but for all students. Collaboration provides an ideal vehicle through which deliberations might take place. This represents a fundamental change in how the roles of special and general educators are viewed in the school setting, whose task becomes one of pooling knowledge about curriculum and current curriculum trends, along with knowledge about how diverse characteristics of learners are expected to interact with the content. The purpose of collaborative discussions and action is to shape the basic structure of what goes on in the classroom to the advantage of all students before the content is presented rather than after the student has failed. As such, collaboration moves us squarely into the realm of curriculum reform.

Maintaining this level of involvement in curriculum reform requires a conscious focusing on the part of both special and general educators on how they interpret the place of curriculum-both past and present-in their shared work. Most likely, general educators will arrive at the curriculum question from a reform context that calls for more rigorous content and increased academic standards for all students by emphasizing in-depth coverage of content, students' abilities to think critically and creatively to solve problems, and integration into the curriculum of concepts that are connected across subject areas (see, for example, Lewis, 1990; Newman, 1988; O'Neil, 1990). Special educators, who tend to have less knowledge about the scope and sequence of the var- 
ious academic areas, will bring their own agenda, most often reflected in concerns that these curriculum reforms will result in more student failure (see, for example, Carnine \& Kameenui, 1990; Glatthorn 1985; Sapon-Shevin, 1987; Shepard, 1987). Special educators' conceptions of curriculum traditionally treat it either as remedial practice as or as whatever has been stated in the individualized education program (for a more thorough discussion, see Pugach and Warger, 1993, in press). If a curriculum that respects diversity in learning is to be achieved, both views must be pursued actively, debated, and integrated.

Making such a shift is hard work for all teachers. Collaboration between special and general education, however, already affords built-in professional support that can be drawn upon for making the structural and conceptual changes that curriculum planning and renewal requires (Pugach \& Wesson, 1995). Making the commitment to becoming knowledgeable about and participating in curriculum in the broad sense enables the development of educational programs in which students can learn challenging, interesting, and motivating content. Defining educational outcomes for students with disabilities from a point of greater curriculum understanding, rather than from the narrow framework that has been traditional in special education, provides educators with unlimited opportunities to set higher expectations and design innovative strategies for reaching them.

In the following examples we describe how collaborative practices between general and special educators can be redesigned as curriculum-centered collaboration both for preventive curriculum planning and for trouble-shooting curriculum problems in the classroom as they arise. Classroom-based curriculum trouble-shooting occurs when special and general education teachers focus specifically on curriculum as the point of problem solving at the classroom level in anticipation of or in response to student difficulty. In contrast, preventive planning comes about through joint participation of special and general education teachers on school or district-wide curriculum planning or renewal teams.

In both examples, what is central is how knowledge and skills can be made more accessible to a wider range of students. By refocusing the traditional source of the problem away from the student and onto the curriculum, the conversation between special and general educators is concerned with broad instructional changes that will be necessary given the new curriculum goals and objectives they choose to enact.

\section{CURRICULUM-CENTERED COLLABORATION AT THE CLASSROOM LEVEL}

In developing a curriculum-centered approach to solving specific classroom problems, we drew on a generic process that already is typical of many collaborative partnerships and is composed of four phases: (a) establishing rapport and setting up the boundaries for collaboration; (b) identifying the problem; (c) developing an intervention plan; and (d) evaluating the collaboration (Aldinger, Warger, \& Eavy, 1991). In each step of this generic process, we have shifted the attention of the conversation away from the student's presenting problem to the curriculum itself. Figure 1 illustrates this curriculum-centered problem-solving process.

In this section we present a description of each phase, along with a vignette depicting how two collaborating teachers might interact. We offer two examples. In the first, the special and general education teachers are planning classroom activities from a curriculum perspective to avoid problems. In the second, teachers collaborate from a curriculum perspective about a classroom situation gone awry.

\section{Classroom Trouble-Shooting}

\section{Phase One}

In the first phase of our curriculum-centered approach, teachers establish rapport and set the expectations for collaboration. If the special and general education teachers are coteaching or when the special educator is providing services in the classroom regularly, beginning this phase at the start of the school year is best. By beginning early, the special educator has an opportunity to gain familiarity with the curricular goals and outcomes for the students in that classroom. In addition, the special educator begins to understand the general educator's teaching style and instructional preferences. Tasks might include surveying materials and giving attention to assessing the learning and behavioral characteristics of the total student group. Similarly, general education teachers make it a point to learn about the special educator's skills and experience and begin thinking in terms of how those assets might be utilized best.

At this time, coming to a preliminary agreement on roles and responsibilities is helpful. Hard questions have to be addressed regarding beliefs and expectations. For example, the perception may linger that the special education teacher will serve primarily as a glorified aide in the classroom. This perception can undermine future efforts to focus jointly on cur- 
riculum because the special education teacher pulls away "the kids with problems," placing primary attention back within an individual-deficit orientation.

Early on, the understanding should be that both special and general education teachers bring expertise to the conversation. Although the content knowledge of special educators is often not as extensive as that of the general educator, the special educator still brings a wealth of knowledge to the partnership, not to mention key expertise in making modifica-

\section{Stage One: Orientation}

Establish rapport

Set limits for collaboration

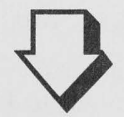

\section{Stage Two: Problem Identification}

Identify new curriculum goals, instructional strategies, and assessment techniques.

Identify new relationships between student, curriculum, teacher, and peers.

Discuss potential mismatch with student characteristics.

Present relevant data.

State potential difficulty area.

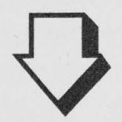

\section{Stage Three: Intervention}

Brainstorm suggestions: curriculum, instruction, assessment.

Select strategies.

Identify support practices for students and/or teachers.

Develop and implement plan.

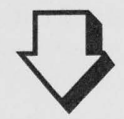

\section{Stage Four: Closure}

Review student progress.

Evaluate.

\section{FIGURE 1}

Curriculum-Centered Problem-Solving Process tions and adaptations. Now is not the time to "defer" to the general educator, as commonly was the case during mainstreaming collaborations. In those collaborations, keeping the child in the general education placement-no matter how much of a problem the standard curriculum was overall-was the overt goal. In contrast, the goal of curriculum-centered problem solving is to pool expertise to improve learning outcomes for all students. The knowledge that special educators bring, particularly with respect to modification and adaptation, becomes much more meaningful if it is implemented through a lens of deep curriculum knowledge.

Jan has been teaching third grade for several years. This will be the first year that Barbara, a special education teacher, has been assigned a teaming placement, so she is not quite sure what to expect.

At the first planning meeting the two went over their expectations. Barbara expressed her apprehensions about being in the general education classroom but emphasized that in no way was her enthusiasm diminished as a result. Jan took the opportunity to spell out her high expectations for student success, particularly as related to the eight special education students on the class roster. Barbara listened and assured Jan that she, too, was committed to providing a strong educational program for all kids. Having found a similar goal upon which to focus, the two teachers began discussing how each could contribute to achieving their joint purpose of student learning.

Clearly, building rapport does not happen overnight. It involves a long-term commitment between the professionals. Even so, there is much to be said for first impressions. The efforts that transpire during this phase can either advance or harm the impending collaborative work. In the conversation between Barbara and Jan, neither made the assumption that Jan was interested only in curriculum or that Barbara was interested only in bringing her "bag of special education tricks" into the classroom.

\section{Phase Two}

In the next phase, problem identification, the goal is to identify potential areas of difficulty in the curriculum for the student(s). The discussion is to include topics such as new curriculum goals, instructional strategies the teachers wish to use to support those goals, and preferred assessment techniques. Take some time to explore the rationale for each point of discussion. At this step, questions for discussion might include the following. 
- Are the goals representative of new curriculum standards? For instance, in mathematics, the curriculum might depart from an emphasis on computational skills to problem-solving skills. In language arts, students might be expected to fine tune their oral discourse skills in addition to their written skills. In science, students might be expected to move beyond completing experiments to generating their own hypotheses for investigation. In social studies, students might be asked to apply their learnings beyond paper-and-pencil tests to solving real problems in the community.

- What prerequisite knowledge and skills do the goals require? Many of the new curriculum trends emphasize the ability to analyze, synthesize, and create (for a thorough discussion, see Pugach and Warger, in press). Application of knowledge is another major focus, especially as it relates to problem solving across disciplines. Many of the new standards also expect students to be able to gather, integrate, evaluate, and present information in a variety of formats. The use of technology often is assumed in higher grades, particularly for tasks such as word-processing and using databases.

- What social skills are needed for the student to participate in the lesson? For instance, cooperative learning assumes a number of critical social skills such as listening, waiting one's turn, taking responsibility, initiating conversation, asking questions, and making group decisions.

- What level of independence is required for students to complete the learning tasks? For example, many inquirybased lessons rely on students to sustain interest over time, to have the necessary cognitive capacities to recall information pertaining to the topic over several days, and to think critically about the information being gathered.

This kind of discussion provides a framework within which the special and general education teachers can reach a clear understanding of student expectations. From this point, teachers are ready to predict potential student difficulties with the curriculum.

Instead of making the assumption that a given student will have difficulty - and having teachers revert to a deficit problem-solving process - the focus of the collaborative dialogue remains on the curriculum goal and instructional strategies the teachers have selected to carry it out. The question becomes: Do the students have the necessary skills and knowledge to succeed in the lesson? To answer this question, teachers scan the group, targeting students who, they speculate, will have particular difficulty because of a mismatch between the goal/instructional approach and the students' skills. At this point additional data might have to be gathered to support their hypotheses. Or the teachers might wish to review students' portfolios or previous work samples to confirm their hunches.

Teachers also need to identify any new relationships that new curriculum goals create among student, teacher, and peers. For example, if the students are expected to solve problems collaboratively, a new relationship-one of interdependency - must be formed between classmates. Or, if students are expected to complete an in depth analysis of a topic, their relationship to the material must be more personal to ensure that they sustain interest over time. In addition, in both cases the traditional relationship between teacher and learner is altered as students are expected to take on more responsibility for their learning.

Jan and Barbara decided that, because the district had moved to a whole-language approach to teaching literacy, this might be a good place to start their work. They planned for a literature-circle activity in which the students would be invited to share their opinions and thoughts about a story. It ends with a clear delineation of potential areas of student difficulty.

The literature-circle activity requires students to sit, wait their turn, and answer when the teacher calls upon them. During the proposed literature-circle activity, students are encouraged to use their critical thinking skills to analyze story elements such as character, plot, and setting. The goal of the activity is for students to use oral discourse skills to share their thinking about the story.

Barbara knew that several of the students had difficulty reading at third-grade level. She also knew that the story Jan wanted to use dealt with concepts that would be new to about a fourth of the class. Finally, Barbara was concerned that if students came to the literature circle without being able to answer the questions, they might react by acting out. Jan agreed with the analysis.

After much discussion, Jan decided that, to her, the most important goal of the lesson was for students to share their learning in a group. She was less concerned with how the students obtained the information, although she did want to encourage a positive attitude toward reading. As a result of the collaborative problem identification, the problem was defined as:

- The lesson requires students to read a story written at a third-grade reading level and to analyze the characters, 
plot, and setting. Some of the students, however, cannot read independently at that level.

- The lesson requires students to comprehend a story in which many of the concepts are new. Further, some of the students, as a result of their life experiences, will have no context for understanding these concepts.

- The lesson requires students to share their thoughts about the story orally with the class in a group-discussion format. Students who have not read the material might become bored and, thus, demonstrate inappropriate behavior.

\section{Phase Three}

With these problem statements in hand, the teachers now are ready to develop ideas to expand, modify, or enhance the curriculum for all students. The teachers also should identify and offer multiple possibilities for enriching the curriculum. If they have to introduce more intensive strategies for certain students, this work should be done only in the context of the specific curriculum goal. Thus, a student might need additional support on a goal this week but not need any help on next week's goal.

In contrast, in traditional problem-centered collaboration, once a student's problem is identified, he or she is almost always expected to need special assistance. The resulting plan should incorporate all of the ideas and suggestions for making the curriculum more accessible to the students. It should draw on the strengths and talents of both collaborating educators.

Jan and Barbara have been brainstorming ideas for how to enhance the lesson to ensure that all students are successful. Here is what they decided:

On Monday, Barbara will introduce the new concepts in the book to the students prior to reading. She will conduct a hands-on activity in which students become familiar with the concepts by relating them to something in their own lives. After this initial activity, she will introduce the story and give them several thought questions to help focus their reading. Students then will be divided into cooperative learning groups to read the story. Members of each group will be allowed to select how they read the material. One student reads while the others listen; each takes turns reading. Once finished, the individual groups will discuss the thought questions the teacher posed earlier. Students will be given time to write their thoughts about the story in their reading logs. Children also will be encouraged to write their opinions about the story in the log, along with any questions they still have. During free time, students can ask either teacher for input on the task.
On Tuesday, students will be invited to participate in the literature circle. The first question Jan will ask the students is whether they liked or disliked the story. Because this question is open-ended, all students will have an immediate chance to participate. She will use a technique called a "whip," in which she goes from child-to-child with the question. During this exchange Barbara will record the students' answers on a flip chart. Next Jan will ask the students to relate what they learned about the new concepts in the story. Finally she will ask the students to think analytically about the characters. Before she calls on a student to answer, however, she will have the students do "think-pair-share," a strategy in which they first think about the answer, then share it with a partner, and finally share it with the entire group.

\section{Phase Four}

In the final phase teachers need a plan for assessing how well students are able to achieve the curriculum outcomes, how students reacted to the new instructional strategies, and whether the assessment captured students' learning well. Questions to be posed at this phase include the following.

- What did the students learn, and how well?

- What did we learn about our students' learning and behavioral characteristics that will help us plan better lessons next time?

In the example, Barbara and Jan built in a number of tactics to be used as performance-based assessment. First, during the warm-up activity Jan took detailed anecdotal notes in the form of a running record. She made notes about which children raised their hands when asked if they had ever heard of a particular concept. She compared these notes to notes taken during the literature-circle discussion. Students in the cooperative groups also were asked to record their group's answers to the challenge questions. Their answers, along with their learning logs, gave the teachers a more detailed account of how students were progressing. Finally, during the literature circle, Barbara kept a record of participating students and their answers.

During the next planning session, Barbara and Jan compared their notes. They found that they had been correct in assuming that a large number of students had no prior experience with the concepts. They also found that all but three students were able to answer questions during the literature circle. In looking back over the data, they found that the three students all had been in the same cooperative learning group. This opened up a new line of discussion as it related to future instructional modifications. 


\section{Classroom Trouble-Shooting After-the-Fact}

At times even the best planned curriculum lesson "fails" in terms of expectations. Planning curriculum to meet students' needs, even planning it collaboratively, does not necessarily guarantee success, although it does tend to increase the probability of success. When a lesson or curriculum unit does not seem to work, the focus still can remain on the curriculum, not the individual students. To identify what should be improved, teachers again can look to the interaction between the curriculum plans and the instructional approach.

At such times, especially if students have gotten out of control, focusing on the child as the source of the problem becomes easy. Our focus on curriculum should not be misconstrued to imply that a student has no responsibility for problems that occur in the learning setting. Rather, our perspective is that the curriculum and its appropriateness or inappropriateness should be considered as one of the first sources of problems. It also is a source over which teachers probably have the largest measure of control.

In addressing a "failed" lesson, we suggest that the collaborating teachers again use the problem-solving process described. This time, though, they are trying to analyze a problem that has occurred already, with the intent of preventing its recurrence.

Students in Bill Rodman's fourth-grade class have just come in from the playground. Mr. Rodman has asked them to pick up math materials laid out on the table in front of the room. He stands at the table, monitoring the students as they come up and get their materials. As Dennis and Carl come up, they trip each other. Mr. Rodman immediately directs both boys to "sit down." Carl starts to complain that "Dennis started it." Mr. Rodman interrupts him and says that if Carl doesn't want to lose his afternoon recess that he needs to sit down. As he sits down, Carl glares at Dennis. Dennis makes a face at him. Carl jumps up and exclaims to Mr. Rodman, "Dennis is making faces."

Mr. Rodman takes a deep breath and tells both boys that their names will go up on the board if he hears another word. Dennis whines, "But I didn't do anything. You're always taking Carl's side against me." Carl makes a face back at Dennis.

Finally, the last student has gotten the materials to be used in a measuring activity. Mr. Rodman orients the students to the assignment, which is to sort the materials by length. Just as he finishes, Dennis takes a measuring stick off Carl's desk, puts it in his nose, and then back onto Carl's desk. Carl mimics loudly: "All right, I told you boys, one more peep and your names go on the board." Carl screams, "I didn't do anything. Dennis picked his nose with my stick, and I ain't gonna use it now."

The class erupts into laughter. Mr. Rodman raps on the table with his ruler to quiet the class. He orders the students to take their rulers and begin measuring the sticks. LaShonda raises her hand and asks, "Which one should we measure first?" Carl calls out, "I'm not measuring the stick Dennis had in his nose." Mr. Rodman glares at Carl and snaps at LaShonda, "the longest one first." LaShonda replies, "but how do we know which one is longest until we measure them?" Mr. Rodman tells the students to put the sticks aside and take out their math books. They will complete a page of multiplication and division problems instead.

Now suppose that you, as a collaborating teacher, had observed this scene and were meeting with Mr. Rodman to go over the lesson. How would you describe the problem? Most likely, Mr. Rodman will see the problem as being Dennis and Carl- "they're constantly fighting and disrupting the class." You might see the problem as Mr. Rodman's inability to manage the classroom and his ineffective instructional techniques. How should this be discussed?

From a curriculum-centered approach, the content of collaboration would focus on what Mr. Rodman wanted his students to know and be able to do. This is not to ignore the issues of classroom management, but the discussion would start with the curriculum. Here's how the problem statements might look:

- The goal is to have students measure real objects. Some students, however, don't have the self-control to handle manipulatives.

- The lesson requires students to exercise independence and respect for each other as they retrieve materials for the task. Some students, however, may not have learned appropriate routines for getting materials.

- The lesson requires students to measure real objects. For most students, this is a new concept they are unfamiliar with.

Given these problem statements, Mr. Rodman and the teacher he collaborates with are in a position to brainstorm solutions. For instance, the students might benefit from seeing him demonstrate the measuring task prior to trying it out themselves. Moreover, he might introduce the measurement task by drawing attention to the purpose of measurement in daily life. Students first might be instructed to measure their deska stationary object-before being given other objects. To structure the measuring task, Mr. Rodman might assign stu- 
dents to small groups in which they measure a large object together. Finally, he likely needs to teach directly the routine to be followed when getting up to get materials.

Exploring the problem through a curriculum lens allows teachers the opportunity to see how instruction can be enhanced and improved. Further, it helps teachers focus on the goals and outcomes of the instruction as the major consideration. If other specific individual interventions are required, they should be initiated only in relationship to an effective curriculum in the first place. Most important, a curriculum focus makes "trying another way" the norm in a collegial setting. All of us make mistakes. None of us are perfect teachers. By taking the judgmental quality out of our collaborations and focusing on the goal of improving student learning, we can move the process of improvement forward more quickly and professionally.

\section{CURRICULUM-CENTERED COLLABORATION FOR BROAD-BASED CURRICULUM PLANNING}

At the classroom level, curriculum-centered collaboration can go a long way in improving teaching and learning for all students. In schools where this sort of collaboration is occurring already, teachers are finding that extending these collegial exchanges to curriculum planning or renewal teams is a logical next step. Acting in advance to prevent problems from a broader perspective redirects the focus to creating positive learning environments that lead to success for all students. Thus, another way to expand the role of special educators is by including them on curriculum renewal teams.

Traditionally, special educators do not participate on curriculum redesign or renewal teams, whether school- or district-wide. Classroom teachers sometimes have not even been offered opportunities to serve on these work groups. Yet these teams typically are where the real proactive, collaborative curriculum work occurs-work that can prevent some of the most common curriculum problems. As new curriculum trends make their way into the district's scope and sequence, prior discussions regarding how that curriculum trend will affect learning are critical to the eventual success of all students.

Understanding curriculum trends is not always easy, especially when the trends themselves may not be consistent. Further, the unprecedented curriculum reform activity that is being undertaken in the various content areas deserves much attention before it can be understood fully. The summary of trends in Table 1 illustrates the sometimes conflicting and controversial nature of some current trends. A clear picture of the meaning and intent of these trends for everyone on the team is essential for responsible curriculum renewal to occur. In the current curriculum reform climate, this means being familiar with the new frameworks in each of the subject areas, as well as the purpose and structure of interdisciplinary approaches to delivering curricula.

When including special and general education classroom teachers on curriculum renewal or redesign teams, the goal is to identify, from a global perspective, whether the knowledge and skills deemed critical for the district's students are really accessible to them. During classroom-based collaborative trouble-shooting, teachers refocus their views about the role curriculum plays in helping or hindering student success. The same concept applies here. Curriculum renewal teams must determine whether students across the district will be able to succeed with the new curriculum goals. The emphasis is still on success, and not on setting up conditions where we know in advance that large numbers of students most likely will fail. If team members suspect that students will not be able to master the goals, the team has to determine how best to address this situation. Curriculum decisions have to be made from the perspective of all the district's students.

A process that we have found to work in directing the discussions follows:

- Clearly identify and define new curriculum trends. The team identifies the specific trends and how they differ from current curriculum practice.

- Determine the impact of these new trends on the curriculum. The trends should be discussed in relationship to the total scope and sequence of the district curriculum.

- Review scope and sequence and determine how and where the new trends best fit.

- Identify specific goals representative of curriculum trends, and infuse them into the scope and sequence.

Here the discussion also should cover prerequisite skills in the sequence that supports attainment of goals at various levels.

- Identify and discuss potential areas of mismatch. What effect will these new goals have on student learning? What will students need to master the goals? From here, the discussion should focus on how the district can build in supports to ensure that all students are successful. 
TABLE 1

Summary of Current Curriculum Trends

\begin{tabular}{|c|c|}
\hline Subject & Trends \\
\hline Mathematics & $\begin{array}{l}\text { Mathematical literacy } \\
\text { Conceptual understanding } \\
\text { Technology } \\
\text { Problem solving } \\
\text { Improving attitudes and expectations about mathematics } \\
\text { Mental computation and estimation } \\
\text { Relationships among concepts } \\
\text { Mathematics across disciplines } \\
\text { Communicating mathematically }\end{array}$ \\
\hline Science & $\begin{array}{l}\text { Clarifying misconceptions } \\
\text { Scientific literacy } \\
\text { Science in society } \\
\text { Science and job skills } \\
\text { Communicating about science } \\
\text { Incorporating scientific material } \\
\text { Process science experiences } \\
\text { Technology } \\
\text { Confronting religion and other ways of knowing }\end{array}$ \\
\hline Social Studies & $\begin{array}{l}\text { History and geography as core } \\
\text { Integrated themes } \\
\text { Values education } \\
\text { Citizenship } \\
\text { Critical thinking } \\
\text { Global interdependence } \\
\text { Understanding individual differences } \\
\text { Integration with other disciplines } \\
\text { Career education/world of work }\end{array}$ \\
\hline Language Literacy & $\begin{array}{l}\text { Whole language/whole literacy* } \\
\text { Writing as a process } \\
\text { Writing across the curriculum } \\
\text { Using language arts to enhance self-esteem } \\
\text { Critical thinking } \\
\text { Focus on social, political, and moral issues } \\
\text { Censorship } \\
\text { Oral discourse/speaking } \\
\text { Return to basics (phonics, skill-based instruction)* }\end{array}$ \\
\hline
\end{tabular}

*Often interpreted/implemented as conflicting trends 
Basically, any curriculum renewal process can be adapted to foster collaboration between special and general educators. The important consideration is to make an explicit effort to consider up front how the curriculum fits the learning and behavioral characteristics of the students and what the district can do to support learning.

Schools can do several things to support teachers who are collaborating around curriculum. Prevention and the longterm goal of improving educational outcomes for all students do not come cheaply. First and foremost, teachers must be afforded time to plan curriculum. To expect teachers to find time "on-the-fly" between classes or before school is not enough. Scheduled blocks of time have to be made available regularly for teachers who are collaborating. Equally important, teachers should be provided professional development around curriculum issues. School districts should devote as much attention to the curriculum as they typically do to new instructional techniques. Further, from our experience in introducing new curriculum frameworks, teachers need adequate time to reflect on what the changes mean to teaching and learning.

Finally, incentives should be built into the system directly. Whether it be released time from mundane tasks such as hall or recess duty to honoraria for participation in extra staff development activities, teachers deserve to be compensated and acknowledged for the additional time and effort they take to revamp classroom practices through curriculum reform.

\section{MAKING A REAL DIFFERENCE THROUGH COLLABORATION}

Although many special and general education teachers engage in collaboration already, the convergence of reform in special education and reform in curriculum provides a unique opportunity to push that collaboration farther than ever before toward meeting students' needs. By pooling their expertise, special and general education teachers can refocus their collective energies on the underlying barriers to student success and begin to design responsive educational programs based on a clear understanding of the goals of the curriculum, and a willingness to rethink the curriculum itself.

Special education has a long tradition of worrying about the quality of the general education program. This issue is all the more critical as the philosophy of inclusion becomes more prevalent. Special educators often have struggled with how best to contribute to improving the educational landscape. Refocusing the process and dynamics of collaboration onto the curriculum itself unveils the potential for literally expanding the range of learning opportunities for students with disabilities - and for all students as well.

As we move toward a curriculum focus for our collegial deliberations, we must think about the meaning of what we ask students to do in school. Once the goals are on the table, special education teachers can take on the role-now redefined - of figuring out what supports will be necessary to assist children in achieving them. We always have asked the question, "What is this student unable to do?" Now the time has come to ask a different set of questions: "Is what we are asking this student to do reasonable?" "Will it lead to important learning?" Finally, "If we agree that the learning goal is important, how do we design the curriculum and classroom tasks to ensure that students are successful?" These are the kinds of questions a curriculum-centered structure for collaboration enables teachers to ask-and to answer together.

\section{REFERENCES}

Aldinger, L. E., Warger, C. L., \& Eavy, P. W. (1991). Strategies for teacher collaboration. Ann Arbor, MI: Exceptional Innovations.

Carnine, D., \& Kameenui, E. J. (1990). The general education initiative and children with special needs: A false dilemma in the face of true problems. Journal of Learning Disabilities, 23(3), $141-144,148$

Glatthorn, A. A. (1985). Curriculum reform and at-risk youth. Philadelphia: Research for Better Schools.

Laycock, V. K., Gable, R. A., \& Korinek, L. (1991). Alternative structures for collaboration in the delivery of special services. Preventing School Failure, 35(4), 15-18.

Lewis, A. C. (1990). Getting unstuck: Curriculum as a tool of reform. Phi Delta Kappan, 71(7), 534-538.

McLaughlin, M. J., \& Warren, S. H. (1992). Issues and options in restructuring schools and special education. College Park, MD: Center for Policy Options in Special Education.

National Association of State Boards of Education. (1992). Winners all: A call for inclusive schools. Alexandria, VA: Author.

Newman, F. M. (1988). Can depth replace coverage in the high school curriculum? Phi Delta Kappan, 69(5), 345-348.

O'Neil, J. (1990). Drive for national standards picking up steam. Educational Leadership, 48(5), 4-8.

Pugach, M. C., \& Warger, C. L. (Eds.). (in press). What's worth knowing? How curriculum trends affect the reform of special education. New York: Teachers College Press. 
Pugach, M. C., \& Warger, C. L. (1993). Curriculum considerations. In J. I. Goodlad \& T. C. Lovitt, (Eds.), Integrating general and special education (pp. 135-148). New York: Charles E. Merrill.

Pugach, M. C., \& Wesson, C. L. (1995). Teachers' and students' views of team teaching of general education and learning disabled students in two fifth grade classes. Elementary School Journal, 95, 279-295.

Sapon-Shevin, M. (1987). The national education reports and special education: Implications for students. Exceptional Children, 53(4), 300-306.
Shepard, L. (1987). The new push for excellence: Widening the schism between regular and special education. Exceptional Children, 53, 327-329.

Warger, C. L., \& Pugach, M. C. (1993). A curriculum focus for collaboration. Learning Disabilities Focus, 18(4), 26-30.

Warger, C. L., \& Pugach, M. C. (1996). Forming partnerships around curriculum: A new focus for inclusion. Educational Leadership, 53(5), 62-65. 